\title{
A study of the Acceptance of Material Incentives and Non-Material Incentives in Agri-Business Companies
}

\author{
Ming Fang, Yan Qi*, Xun Liu, Yan Wang \\ International College Beijing, China Agricultural University, Beijing, China \\ Email: " meganqiyan@sina.cn
}

Received March 2014

\begin{abstract}
As a vital part of an organization, human resources management has been drawing broad attention both industrially and academically. Motivation is a significant content of HRM, which can be divided into material incentive and non-material incentive. This paper investigated the Chinese agri-business companies' motivation methods and gave suggestions. This paper uses questionnaire and statistical analysis to explore and confirm that agriculture companies should pay attention not only to material incentive, but also non-material incentive. A Chinese agri-business company has been chosen for study.
\end{abstract}

Keywords

Human Resource Management, Incentive, Agri-Business

\section{Introduction}

China is a large country of agriculture. In 2010, the total sales of all agri-business companies are 2.52 billion Yuan that increases at a rate of $37 \%$ and is 19.4 times than that of 1999. Although agri-business in China rapidly expands, staff who work in agri-business firms of China often cannot feel motivated enough during work. Therefore, the Chinese agri-business firms have lower capital and benefit and slower development than those in some advanced foreign countries. In U.S. there were 2473 agri-business cooperatives and they had total assets of 691 billion dollars and net worth of 230 billion dollars in 2008 [1].

There are three reasons resulting in this problem. Firstly, the employees' quality is lower than that in other industries. Secondly, the Chinese agri-business enterprises do not have enough capital. Thus the incentive system increases the cost for companies. Some firms cannot afford the cost which they do not think essential, which caused the agri-business companies to ignore the incentive system. Thirdly, some agri-business companies usually pay attention to material incentives, especially to motivate employees via increasing salary, but ignore the non-material incentives (spirit motivation), which results in the lack of staff's total attention and whole potential [2].

Due to the rapid development of China's economy, employees' needs are changing. There is a trend that the 
material motivation methods cannot satisfy employees’ needs. The agri-business companies with low capacity of incentives for staff cannot attract more highly qualified staff, which leads to the loss of core competitiveness of the companies. Therefore, increasingly more agri-business companies started to highlight the importance of motivation strategies and to build up a sophisticate system to manage the human resources. They pay attention to both non-material incentive and material incentive to motivate employees.

\section{Literature Review}

There are many papers related to human resource management including the incentive, training, performance appraisal and staff quality, etc. One of the most crucial is incentive that occupies large percentage in the literature concerned.

Atkinson claimed motivation is direction of moment action, intensity and continuity of direct impact in 1964 [3]. Motivation can be seen as a strong desire to achieve a certain goal accompanied with the appropriate energy and determination to make it a reality. Having the patience and motivation to move closer to the goal one step at a time is what will eventually lead to success [4]. For the study on motivation, Maslow's theory and two factors theory are popularized for the adoption and further study.

\section{a) Maslow, theory of human motivation psychological review}

Maslow put forward the theory of human motivation psychological review in 1943. The theory presents the needs hierarchy of five classes. From lower to higher level of needs, the five classes are physiological needs, safety and security, love and belonging, self-esteem, and self-actualization [5]. When people's needs are satisfied they would produce higher demands. Then the incentive system emerges. Companies give motivation to different staff of various needs. The theory covers two areas. One is material incentive and the other is non-material incentive. Physiological need is the material incentive and the other four contents are non-material incentives. However overweighing the attention to material incentive would result in people's lack of needs of spirit and effect of incentive is transitory but not material. At the start, most people work hoping to get well material incentive. And after that people begin to chase higher level of incentive, that is, non-material incentive. It indicates the spiritual rewards, such as the recognition, promotion, praise, achievement responsibility and personal growth. Non-material incentive often does not need too much invention, but it can generate effective management to help employees use their potential when they work [6].

\section{b) Two factors theory}

The American scholar Herzberg pointed out that the employees were satisfied or unsatisfied because of their different work. The satisfaction degree comes from people's work. Dissatisfaction factor cannot generate motivation for people, but satisfaction factor generates mental motivation that can facilitate everyone to try their best to realize themselves. Moreover Herzberg advocated that one who had motivation can acquire authentic incentive. Therefore, he generated some incentive measures, including the increase of income, welfare, training of interpersonal relation, and communication skills [5].

Drucker contended money which was taken for motivation in current industry society was not the main source for motivation. Li (2002) indicated that pure material incentive could not satisfy employees' needs sufficiently and promote positivity for employees effectively. And staff might over depend on incentives, which might result in the increase of company's cost and the decrease of marginal benefit.

According to Maslow's theory and two factors theory, motivation system can encourage one's potential that can help him to have better performance in the work. A psychological study shows, people only play $10 \%-30 \%$ potential. With material motivation employees can play 50\% - 80\% potential. And non-material incentive can make people play $80 \%$ - $100 \%$, even $100 \%$ potential [7]. The material incentive is always based on the physical foundation, and the non-material incentive on the organizational culture. They can improve people's positivity, initiative and creativity when they work. And material incentive is fundamental. Motivation not only brings benefits to employees, but also brings firms efficiency and effectiveness. The managers should pay enough attention to the two incentive methods and balance between them. The companies can achieve their goal easier, if the employees have passion. As human resource management of agri-business companies in China is not sufficient, currently mainly depending on material incentive, it remains an issue in human resources management.

Based on Maslow's theory and two factors theory, this study developed the frames to explore the acceptance of material incentives and non-material incentives in agri-business companies. The findings of this empirical study may provide the strategies of human resource management for agri-business companies. 


\section{Methods}

For the investigation, both primary data and secondary data were used. When collecting the primary data, the employees of a Chinese agri-business company were selected. The paper selected a Chinese agri-business company located in Beijing as a case for study. Built in 1956, the company has 5001 employees, and 2311 of whom have received higher education. The company owns 2000 science and technology achievements and 195 national patents. It is renowned in agriculture area, so it can represent the Chinese agri-business firms and reflect some common problems of them.

The questionnaire was adopted with a sample size of 120 . The basic information of the participants has been summarized in Table 1. The questionnaires were sent to the common employees and managers in the Chinese agri-business company. And 112 effective questionnaires were received. From the investigation, the common employees' thoughts about which incentive methods could motivate them a lot were discovered. The managers talked about the business incentive mechanism. For data processing and analysis, the SPSS software was used. This study accommodated gender, age and education background in order to understand different types of people's various incentive needs including material incentive and non-material incentive. Some people have mixed needs that are both material incentive and non-material incentive. Thus if the enterprise only has material incentive, the motivation for staff cannot be maximized. Firms would better rely on the characteristics of their staff and the situations of the company to determine the motivation measures. The incentive system should include both material and non-material incentive. The secondary data were acquired from the papers on authoritative websites, such as Science Direct.

\section{Results}

Based on the investigation, the incentive system is very important for the agri-business companies. However, it

Table 1. Basic information of the participants.

\begin{tabular}{|c|c|c|}
\hline Questions and Choices & Amount & Percentage \\
\hline \multicolumn{3}{|l|}{ What is your gender? } \\
\hline A Female & 59 & $53 \%$ \\
\hline B Male & 53 & $47 \%$ \\
\hline Total & 112 & $100 \%$ \\
\hline \multicolumn{3}{|l|}{ What is your age? } \\
\hline A $18-25$ & 13 & $12 \%$ \\
\hline В $26-35$ & 51 & $46 \%$ \\
\hline C $36-45$ & 19 & $17 \%$ \\
\hline D $46-55$ & 19 & $17 \%$ \\
\hline Total & 112 & $100 \%$ \\
\hline \multicolumn{3}{|c|}{ What is your education background? } \\
\hline A Junior college & 14 & $13 \%$ \\
\hline B Undergraduate & 60 & $54 \%$ \\
\hline C Postgraduate & 31 & $28 \%$ \\
\hline D Doctor & 7 & $6 \%$ \\
\hline Total & 112 & $100 \%$ \\
\hline \multicolumn{3}{|l|}{ What is your duty? } \\
\hline A Official & 82 & $73 \%$ \\
\hline B Division manager & 25 & $22 \%$ \\
\hline C Top manager & 5 & $5 \%$ \\
\hline Total & 112 & $100 \%$ \\
\hline
\end{tabular}


is found that most of the participants had low working fervency. It is obvious that the incentive mechanism of the agri-business company is not faultless. After the analysis of the investigation results, some problems are identified.

\section{a) Unbalance of material incentive and non-material incentive}

As the results indicate that ninety percent participants thought they not only should have material incentive but also should have other spiritual, such as more free working time and better organizational culture. In the prior years, most of the agri-business companies had the employees who did not have high level of education. In those years, the material incentive worked very well. With the development of the agri-business companies, the technological elements for them have been becoming more and more important. That is to say, the education levels of the employees are much higher than before. According to the results, thirteen percent participants graduated from junior college, fifty-four percent participants were undergraduates, twenty-eight percent participants were postgraduates, and six percent people were doctors. Among all the respondents, fifty-nine percent participants were undergraduates; and twenty-six percent participants were postgraduates. Nevertheless, we found that the major inventive mechanism of the modern agri-business companies is still the material incentive. Most of the agri-business companies still think it is enough for them to offer the material incentive. Only few of them put the material and non-material incentive at the same position. However, the people who have high levels of education cannot be satisfied with the sole material incentive. They need more spiritual incentives to improve their spiritual life.

b) Shortage of the specific awards standards

From the results, it is found that more than half of the participants' companies have the specific awards standards. Together with the data found before, most of the agri-business companies only provide the fixed number of the wages without specific awards standards. Many employees even don't know whether they are offered the material or non-material incentive.

According to previous statistics, $80 \%$ companies hoped that at least eighty percent of the products are exempted from income tax related to distribute dividends and other parts which are related with the incentives [8]. Although this could help save the companies the money, it would be harmful to the performances of the agri-business companies. From the reflections of the participants, most of them would not work hard if there were no incentives. That is to say, if the agri-business companies don't release the specific incentive mechanisms to the employees, they would not have motivation to work hard, because they think even if they have much better performances, they would receive the same treatment with those whose performances are common. Therefore, the employees wouldn't devote themselves to achieving the goals. Although some may accomplish their tasks, they would never want to do extra work. Another harmful thing this problem may bring is bribery. In the companies which don't have the specific awards standards, the briberies must be common, especially between the employees and the middle management. Because there is no specific awards standards, if the employees want to get satisfactory awards they must have a good relation with their boss. Some middle managers make use of this to make money. Thus, the phenomenon of bribing is difficult to avoid in the companies which don't have the specific awards standards.

There are also other problems, such as the shortage of personal feedback channels, the company's failure of realizing the incentive scheme, the employees' dissatisfaction with others' awards and so on. No matter what kind of incentive problems the agri-business companies have, these are all caused by the improper cognition and management of the incentive system.

\section{Discussion}

In recent years, the incentives of human resources management has been attached more importance and it has been playing a vital role in determining the performances of the companies. As the data show that despite a challenging economy, the incentive industry is booming. U.S. organizations spend over $\$ 100$ billion annually on developing programs that attract, retain and motivate their employees [9]. However, as mentioned above, many agri-business companies can't make good use of the incentives and thus have some leaks. After the analysis and discussions of the actuality, some main reasons and solutions for these agri-business companies have been achieved as follows.

a) Traditional conception restricts incentive mechanism of agri-business companies

Number footnotes separately in superscripts. Place the actual footnote at the bottom of the column in which it 
was cited. Do not put footnotes in the reference list. Use letters for table footnotes.

As the investigation indicates, seventy-eight percent participants thought the companies should use both the material and non-material incentives. Nevertheless, in the agri-business companies in China, the material incentive is still in the highest flight. For the managers of the agri-business companies, they think the single material incentive is sufficient, because they haven't attached enough significance to the management of the agri-business companies and think it is enough for the employees to have just the material incentive. Most of the companies only use the administrative measures to enforce the employees to achieve their goals and deprive the rights of having holidays. They just want to use the salary increase to encourage the employees and ignore their spiritual needs, which weakens the motivation to the employees.

This study suggested that the agri-business companies should import the advanced ideas of managing the incentive mechanism. For example, the agri-business companies can use different kinds of incentives for different employees. The top managers should consider the individual difference sufficiently. For the employees mainly engaged in manufacturing, the average education background of them is usually not very high, so the primary incentive needs of them are mainly made up of the material incentives, that is, the cash rewards. The companies can use material incentive to encourage them to improve the production efficiencies. However, the university graduates or those who have already had steady life want both great incomes and the satisfactions of the spirit, such as the working environment, cultural atmosphere. For these employees, the organizations should consider the non-material incentive as well. Therefore, the modern agri-business companies should not only use the traditional incentive methods but also try to use the new incentive mechanism which can fit the present situation, so as to receive the best incentive effect.

\section{b) Neglect of the organizational culture}

For the incentive mechanism, the organizational culture is an indivisible factor for both the material and nonmaterial incentives. People have had the "lack of demands" and "growth needs", ever since one person has set up a goal. It's a motivating progress [10].

For the material part, if the agri-business companies don't have proper organizational culture, the employees wouldn't understand the incentive scheme well. They would put the awards at the first place. Even if the material awards decrease a little, they would never work as hard as before. What is more, without a perfect organizational culture, there must be conflicts among the employees. For example, although the employees are all given suitable awards for themselves, they would think it unfair for them if there is any difference among them.

For non-material incentive, the function of the organizational culture should not be neglected either. As everyone knows, the needs for the non-material incentive are different from the needs for the material incentive. People always have different kinds of spiritual needs. The organizational culture can affect the employees' understanding of the non-material incentive. For example, the need for the working environment is one kind of the non-material incentive. Without a good organizational culture, the employees would unreasonably pursue the physical conditions and infrastructures. On the contrary, with a harmonious cultural atmosphere, the employees would think that if the working environment can ensure and promote the communications among the employees, it would be a good environment for work. What is more, the managers can also affect the organizational culture. The managers should build an equal relation with the employees. Only in this way, the employees would be willing to communicate with their bosses and feel easy to work, which can contribute to the achievement of the non-material incentive. To conclude, the culture of one company is highly related with its incentives. So if the companies want to express the functions of the incentives completely, they must pay more attention to improve the organizational culture and make it suitable for itself.

\section{Conclusion}

This study explores the problems that the Chinese agri-business companies have and confirms that the material and non-material incentives should be used together to make the incentive mechanism complete. The following conclusions are reached: (1) Most of the agri-business companies in China have already realized the importance of the incentives. But they should put the material and non-material incentive at the same position; (2) If the companies intend to make good use of the incentive mechanism, they must pay attention to the other related aspects which can affect the implementation of the incentive scheme, such as the organizational culture; (3) The agri-business companies should attempt to attract more better educated employees. They can invent new agricultural technologies and equipment. 
The primary restriction of the research is that it can't cover all kinds of the agri-business companies in China. The sample companies in research are limited in the same city, which affects the representativeness of the research. The selected companies represent the modern ones in this industry which can suit the current needs. But they are different from some traditional Chinese agri-business companies.

The future research should cover the issues of the modern Chinese agri-business companies and compare their conditions with those of the foreign agri-business companies. Although the scales of the advanced foreign countries are not as big as China, most of them have modern management ideas for the agri-business sector. Those advanced management ideas are useful in finding the exact weaknesses of the agri-business companies in China and help the managers of the Chinese agri-business companies improve the company performances.

\section{References}

[1] Rural America, Agricultural Development and Enlightenment. www.csh:.gov.cn, http://www.csh.gov.cn/article_364505.html

[2] Wu, C. (2011) Problems and Countermeasures of Agricultural Enterprises Incentive Mechanism in Human Resource Management. Modern Agricultural Sciences and Technology, 15, 1-3.

[3] Yu, Z. (2005) Motivate Salesman and Performance Management.

[4] What Is Motivation, 2012. http://whatismotivation.net/

[5] Wang, Z. (2009) The classical theory of incentive mechanism. The Fortune Times, 2, 73.

[6] Zhao, Y. (2009) Staff non-material incentive design and application.

[7] Liu, Q. Zhu, L. (2009) Research of staff non-material motivation system. China Management Informationization, 2,73.

[8] Diouf, A. (2012) Senegal looks to expand agribusiness sector http://www.tradeinvestafrica.com/investment_opportunities/151400.htm

[9] Finding the Right Incentive Company and Programs Finding the Right Incentive Company and Programs that Work, HR Management: http://www.hrmreport.com/article/Finding-the-Right-Incentive-Company-and-Programs-that-Work/

[10] Li, D. (2012) Enterprise culture incentive mechanism. China cultural service: http://www.fwwh.net/list.asp?id=621 